\title{
Erratum to: Dynamic posterior stabilization for degenerative lumbar spine disease: a large consecutive case series with long-term follow-up by additional postal survey
}

\author{
R. Greiner-Perth ${ }^{1}$ - N. Sellhast ${ }^{2}$ - G. Perler ${ }^{3}$ D. Dietrich ${ }^{3,4} \cdot$ L. P. Staub ${ }^{3}$. \\ C. Röder $^{3}$
}

Received: 26 April 2016/Revised: 26 April 2016/Accepted: 26 April 2016/Published online: 3 May 2016

(c) Springer-Verlag Berlin Heidelberg 2016

\section{Erratum to: Eur Spine J \\ DOI 10.1007/s00586-016-4532-2}

Unfortunately, the blinded version of the manuscript was published. The patients included in the study were treated at the Orthopedic Center Hochfranken, Münchberg, Germany. Ethics approval was obtained through the German arm of the Spine Tango registry from the ethics committee of the University Hospital Cologne (No. 09-182), where the German Spine Tango server module is located.

The online version of the original article can be found under doi: 10.1007/s00586-016-4532-2.

\footnotetext{
L. P. Staub

lukas.staub@ispm.unibe.ch

1 Orthopädische und Neurochirurgische Gemeinschaftspraxis, Eppenreuther Straße 28, 95032 Hof, Germany

2 Regionalspital Emmental AG, Hospital Burgdorf, Oberburgstrasse 54, 3400 Burgdorf, Switzerland

3 Institute of Social and Preventive Medicine, University of Bern, Finkenhubelweg 11, 3012 Bern, Switzerland

4 Institute for Mathematical Statistics and Actuarial Science, University of Bern, Sidlerstrasse 5, 3012 Bern, Switzerland
} 